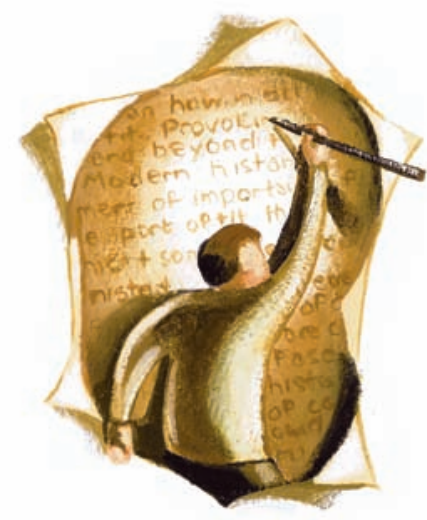

\section{Diet and weight loss}

Irene Strychar's recent review of diet in the management of weight loss ${ }^{1}$ contains some incorrect and biased statements. For example, according to the author, during very-low-carbohydrate intake, "the body depletes its glycogen stores, and gluconeogenesis is induced, whereby lean tissue is used to produce glucose as an energy source for the brain." This statement is clearly fallacious. True, animals share the metabolic deficiency of the total (or almost total) inability to convert fatty acids to glucose. Thus, the primary substrate for gluconeogenesis is amino acid, with some help from glycerol (obtained from fat tissue triglycerides). However, when the rate of mobilization of fatty acids from fat tissue is accelerated, as, for example, with a very-low-carbohydrate diet, the liver produces ketone bodies. The liver cannot use these ketone bodies, which therefore flow from the liver to extrahepatic tissues (e.g., brain, muscle) for use as a fuel. Simply stated, ketone body metabolism by the brain displaces glucose utilization and thus spares muscle mass. In other words, the brain derives energy from storage fat during consumption of a very-low-carbohydrate diet.

Numerous studies indicate that a diet low in carbohydrate and high in protein is, if anything, protective against loss of muscle mass during energy restriction. ${ }^{2-4}$ This topic is covered in detail in 2 recent reviews. ${ }^{5,6}$

\section{Anssi Manninen}

Senior Science Editor

Advanced Research Press, Inc.

\section{REFERENCES}

I. Strychar I. Diet in the management of weight loss. CMAJ 2006;174(I):56-63.

2. Young CM, Scanlan SS, Im HS, et al. Effect of body composition and other parameters in obese young men of carbohydrate level of reduction diet. Am J Clin Nutr 1971;24:290-6.

3. Willi SM, Oexmann MJ, Wright NM, et al. The effects of a high-protein, low-fat, ketogenic diet on adolescents with morbid obesity: body composition, blood chemistries, and sleep abnormalities. Pediatrics I998;I0I:6I-7.

4. Volek JS, Sharman MJ, Love DM, et al. Body composition and hormonal responses to a carbohydrate-restricted diet. Metabolism 2002;51:864-70.

5. Manninen AH. Is a calorie really a calorie? Metabolic advantage of low-carbohydrate diets. J Int Soc Sports Nutr 2004;I(2):2I-6.

6. Manninen AH. Very-low-carbohydrate diets and preservation of muscle mass. Nutr Metab (Lond) 2006;3:9.

DOI:I0.I503/cmaj.1060022

\section{[The author responds:]}

In my review of low-carbohydrate diets in the management of weight loss, ${ }^{1}$ the statement about the depletion of glycogen stores and induction of gluconeogenesis ("whereby lean tissue is used to produce glucose as an energy source for the brain") refers specifically, as noted in the same paragraph, to the initiation of an Atkins diet, which limits carbohydrate intake to as little as $20 \mathrm{~g} /$ day. Soon after, as ketogenesis sets in, glucose is indeed displaced by ketone bodies as the predominant fuel for the brain, thus reducing the need for glucose synthesis from amino acids and sparing muscle mass.

Randomized controlled studies, ${ }^{2-4}$ as referenced in my review, have shown that low-carbohydrate diets, with notintended or intended similar calorie restrictions, reduce lean body mass more than low-calorie diets. The calorie intake, the protein and carbohydrate content of the diet, the duration of the diet, the compliance to a restricted amount of carbohydrates to sustain ketoacidosis, and the age, physical activity and clinical condition of the subject are all factors that influence changes in lean body mass. It is not surprising, therefore, that articles such as those cited by Anssi Manninen indicate other effects on lean body mass status, which explain current controversies and justify further research.

\section{Irene Strychar}

Department of Nutrition

Faculty of Medicine

Research Centre of Notre-Dame Hospital

Centre hospitalier de l'Université de Montréal

Université de Montréal Montréal, Que.

\section{REFERENCES}

I. Strychar I. Diet in the management of weight loss. CMAJ 2006;174(I):56-63.

2. Brehm BJ, Seeley RJ, Daniels S, et al. A randomized trial comparing a very low carbohydrate diet and a calorie-restricted low fat diet on body weight and cardiovascular risk factors in healthy women. J Clin Endocrinol Metab 2003;88:1617-23.

3. Yancy WS, Olsen MK, Guyton JR, et al. A low-carbohydrate, ketogenic diet versus a low-fat diet to treat obesity and hyperlipidemia. Ann Intern Med 2004;I40:769-77.

4. Meckling KA, O'Sullivan C, Saari D. Comparison of a low-fat diet to a low-carbohydrate diet on weight loss, body composition, and risk factors for diabetes and cardiovascular disease in free-living, overweight men and women. J Clin Endocrinol Metab 2004;89:2717-23.

DOI:Io.I503/cmaj.Io6or45

\section{Cycling without a helmet}

An advertisement for Atacand (candesartan cilexetil) that appeared in several issues of CMAJ in 2006 shows an older man on a bicycle without a helmet and asks, "Where will his heart take him today?" Without a helmet, his heart may help him to pedal to intracranial disaster!

$C M A J$ needs to demand that advertisers set a better example.

\section{Sarah Giles}

RI Family Medicine

Thunder Bay, Ont.

DOI:I0.I503/cmaj.1060053

Editor's note: Any drug advertisement submitted for publication in $C M A J$, including the ad described in this letter, must have prior approval from the Pharmaceutical Advertising Advisory Board (PAAB). Beyond that, CMAJ has little control over the content of PAAB-approved drug ads. We strongly support the use of bicycle helmets, and publication of this ad was not intended to indicate otherwise. We have brought this to the attention of the advertiser in question and thank Sarah Giles and other readers for bringing this to our attention. 